\title{
INFORMATION
}

\section{EVGENII STEPANOVICH LUKIN On his 70th birthday}

Translated from Steklo i Keramika, No. 7, p. 46, July, 2013.

\begin{abstract}
Evgenii Stepanovich Lukin, Doctor of Technical Sciences and Professor in the Department of Chemical Technology and Refractory Materials at D. I. Mendeleev Russian Chemical Technology University, celebrated his 75th birthday on July 31, 2013.

E. S. Lukin was born in 1938 into the family of an office worker in the town of Balashikha in Moscow Oblast'. After completing secondary school in 1956 E. S. Lukin entered the D. I. Mendeleev Moscow Chemical Technology Institute; he graduated in 1961 with honors. He remained to work in the Department of the Chemical Technology of Ceramic and
\end{abstract} Refractory Materials as a senior

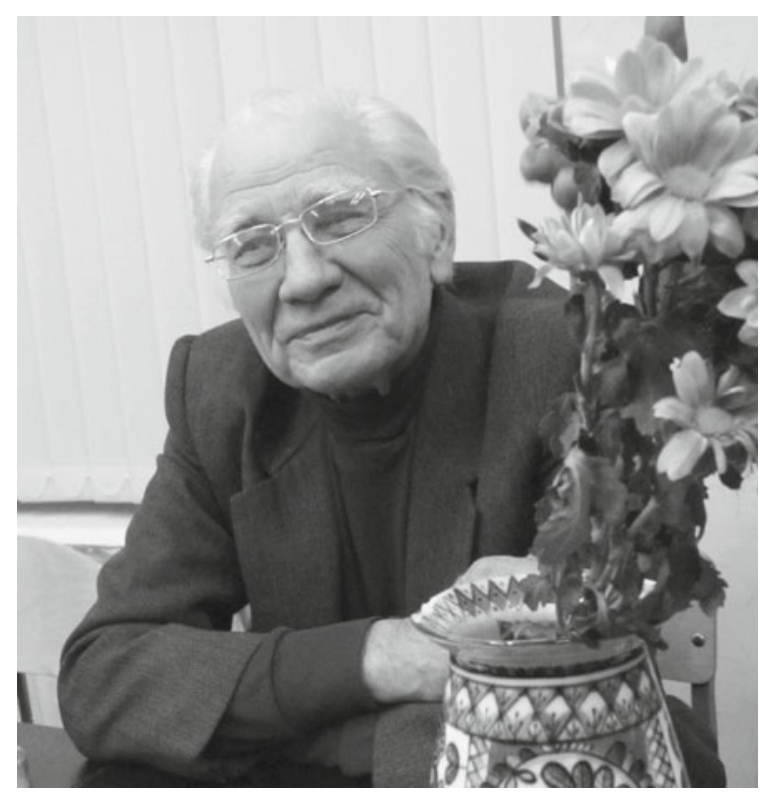

machine building, atomic industry, electronics and other fields of industry.

Over this time E. S. Lukin trained more than 320 engineers and technicians, 24 candidates of science and one doctor of science. E. S. Lukin is a coauthor of five monographs, the main practicum in the technology of ceramics and refractories, coauthor of a new textbook and practicum by profession. E. S. Lukin is the author of about 340 articles, 51 inventor's certificates and 15 patents.

In 1976-1982 E. S. Lukin worked as a deputy dean and in $1988-1992$ as dean of the faculty. E. S. Lukin is an active member of the Academy of Engilaboratory assistant. E. S. Lukin served as a research associate and assistant (1964-1968) and associate professor $(1968-1988)$. He has served as a professor in the department since 1988 .

In 1965, without leaving his main job E. S. Lukin defended his candidate's dissertation 'Investigation of the certain high-temperature properties of ceramics of pure oxides'. In 1988 he defended his doctoral dissertation 'High-density oxide ceramic with regulatable microstructure'. In 1989 he was confirmed in the rank of professor. In his doctoral dissertation E. S. Lukin formulated the basic laws of a phenomenon in ceramic technology whereby a phase inherits the properties of the immediately preceding phase, which is very important for developing compositions and technology of ceramic materials with prescribed structure and properties.

E. S. Lukin combined his pedagogical work with fruitful scientific research. He is well known for his scientific work on the technology of ceramics, predominately in the field of technical ceramics - producing nanopowders, high-strength ceramics and ceramic-matrix composites, transparent ceramics, high-porosity ceramics and bioceramics based on hydroxyapatite. The materials developed by E. S. Lukin are used in aircraft manufacturing, space technology, medicine, neering Sciences, International Academy of Informatization, Russian Academy of Natural Sciences, member of the editorial board of the journal Novye Ogneupory and a member of dissertation committees at D. I. Mendeleev Russian Chemical Technology University and V. G. Shukhov Belgorod State Technological University.

E. S. Lukin was awarded the titles Inventor of the USSR, Excellence in Higher Education and Honored Worker in Higher Education. He was awarded the gold medal of the Ministry of Higher and Secondary Special Education and a gold medal of All-Russia Exhibition Center. In 2013 he was awarded that highest award of the Academy of Engineering Sciences - the N. N. Semenov Medal.

E. S. Lukin enjoys fame and respect among scientists and workers in the ceramic industry not only in Russia but also abroad.

The staff in the Department of the Chemical Technology of Ceramic and Refractory Materials at the D. I. Mendeleev Russian Chemical Technology University and the editorial board and editorial staff of the journal Steklo i Keramika congratulate Evgenii Stepanovich on his memorable anniversary and wish him happiness, good health and new creative achievements for the good of the science of ceramics. 